\title{
Identification of Castasterone and Brassinone from Immature Seeds of Pharbitis purpurea
}

\author{
Yoshihito SUzuKI, Isomaro Yamaguchi and Nobutaka TAKAHASHI \\ Department of Agricultural Chemistry, The University of Tokyo, \\ Bunkyo-ku, Tokyo 113, Japan \\ Received May 29, 1984
}

\begin{abstract}
While investigating the occurrence of brassinolide homologues in immature seeds of Pharbitis purpurea, castasterone and brassinone were identified in quantities of about $1.1 \mu \mathrm{g} / \mathrm{kg}$ f.w. and $0.2 \mu \mathrm{g} / \mathrm{kg}$ f.w., respectively.
\end{abstract}

Since brassinolide was isolated from rape pollen as the first steroidal plant growth regulator, ${ }^{1)}$ intensive research on the investigation and isolation of active substances related to brassinolide in higher plants has been continued. Before 1982, when this study was done, as many as nine brassinolide homologues had been characterized from natural sources, ${ }^{2 \sim 6)}$ suggesting a wide structual variation in this group and their wide distribution in the plant kingdom.

In our series of studies on the plant growth regulators in Convalovulaceae, we investigated the occurrence of brassinolide homologues in immature seeds of Pharbitis purpurea.

The immature seeds $(27 \mathrm{~kg})$ of $P$. purpurea were extracted with $80 \%$ aqueous acetone and the extract was concentrated in vacuo affording an aqueous concentrate which was successively extracted with benzene, ethyl acetate and $n$ butanol. Aliquots of each organic extract were submitted to a lamina inclination test ${ }^{7)}$ which is the most sensitive bioassay for brassinolide homologues. The activity was detected only in the benzene extract, which was further fractionated into an acidic benzene soluble fraction and a neutral benzene soluble fraction. The neutral benzene soluble (NBz) fraction $(278 \mathrm{~g})$ showing biological activity was subjected to a five-transfer countercurrent distribution between methanol-water $(9: 1)$ and $n$ hexane-benzene $(9: 1)$, and the two polar frac- tions showed biological activity (Fig. 1). The active fractions were combined $(145 \mathrm{~g})$ and purified by repetitive silicic acid adsorption chromatographies, affording an active concentrate $(138.2 \mathrm{mg}$ ) (Figs. 2 and 3), which was submitted to further purification by HPLC.

GPC on Shodex H-2001 of the active con-

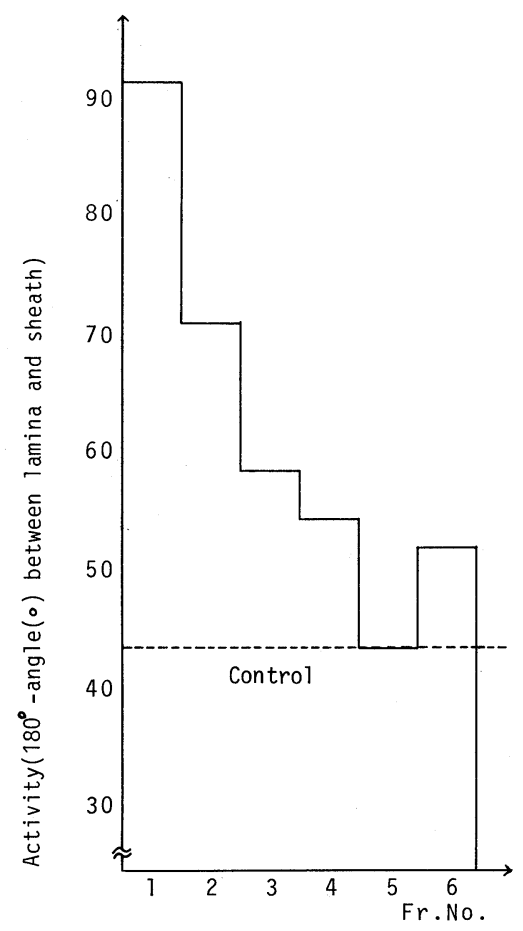

FIG. 1. Histogram of Biological Activity of the Fractions from Countercurrent Distribution. 


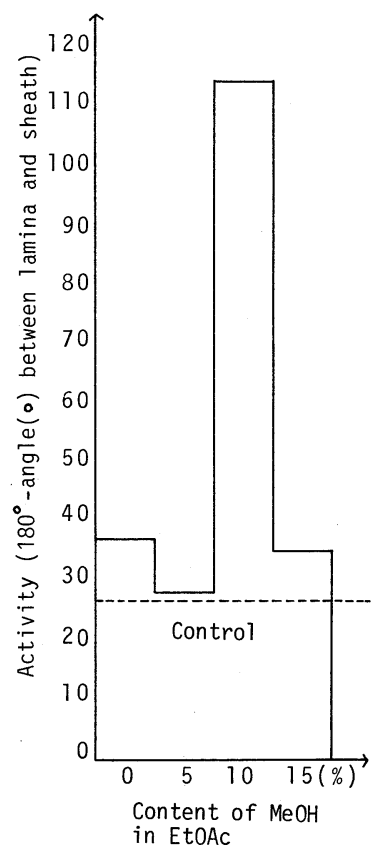

FIG. 2. Histogram of Biological Activity of the Fractions from Silica Gel Adsorption Chromatography (1).

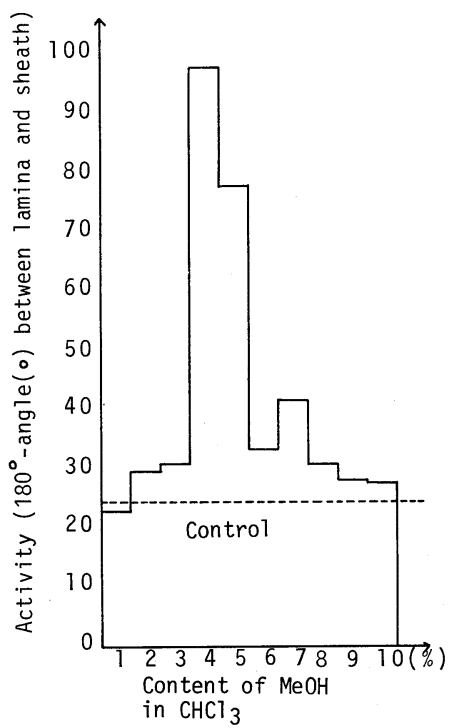

FIG. 3. Histogram of Biological Activity of the Fractions from Silica Gel Adsorption Chromatography (2).

centrate gave 15 fractions. As shown in Fig. 4, a fraction of $t_{R} 20^{\prime}-21^{\prime}$ (Fr. A, $10.5 \mathrm{mg}$ ) was found to be predominant, and another of $t_{R}$

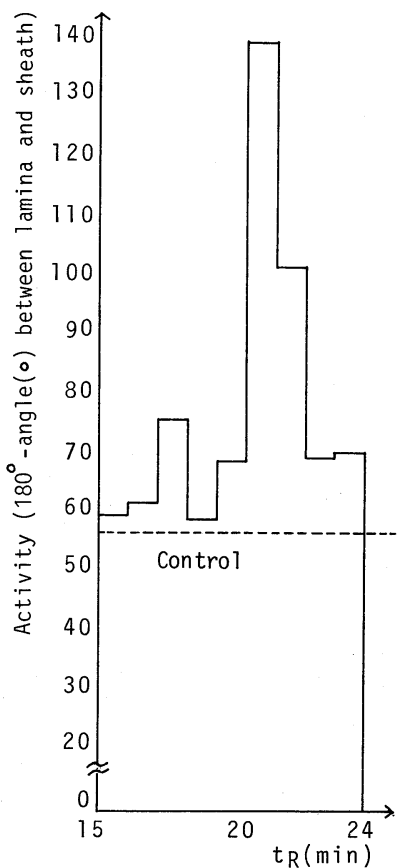

FIG. 4. Histogram of Biological Activity of the Fractions from Shodex H-2001.

$21^{\prime}-22^{\prime}$ (Fr. B, $5.4 \mathrm{mg}$ ) to be a minor active fraction.

Prior to purification of the main fraction (Fr. A), the chromatographic behavior and characteristics of the active components were examined using Fr. B. Fr. B was further purified by HPLC on Nucleosil 5CN eluted with acetonitrile-water and four active fractions (B-CN-1 to B-CN-4) were obtained. These four active fractions were combined and treated with methaneboronic acid in pyridine, ${ }^{8)}$ and subjected to $\mathrm{GC} / \mathrm{MS}$ and $\mathrm{GC} /$ High MS. The mass chromatogram of the ions of $\mathrm{m} / z 512$ and $\mathrm{m} / z 498$ showed a peak of $\mathrm{m} / z 512$ at $t_{R} 4.0 \mathrm{~min}$ and two peaks of $\mathrm{m} / z 498$ at $t_{R} 4.0$ and $3.3 \mathrm{~min}$. The full spectrum at $t_{R}$ $4.0 \mathrm{~min}$ was superimposable with that of the bismethaneboronate of castasterone (Fig. 5). The high resolution MS showed the compositions of the ions $m / z 512$ and $m / z 155$ to be $\mathrm{C}_{30} \mathrm{H}_{50} \mathrm{O}_{5} \mathrm{~B}_{2}$ and $\mathrm{C}_{8} \mathrm{H}_{16} \mathrm{O}_{2} \mathrm{~B}$ respectively. The former is the molecular ion of the bismethaneboronate of castasterone and the latter is the characteristic fragment ion due to side chain 

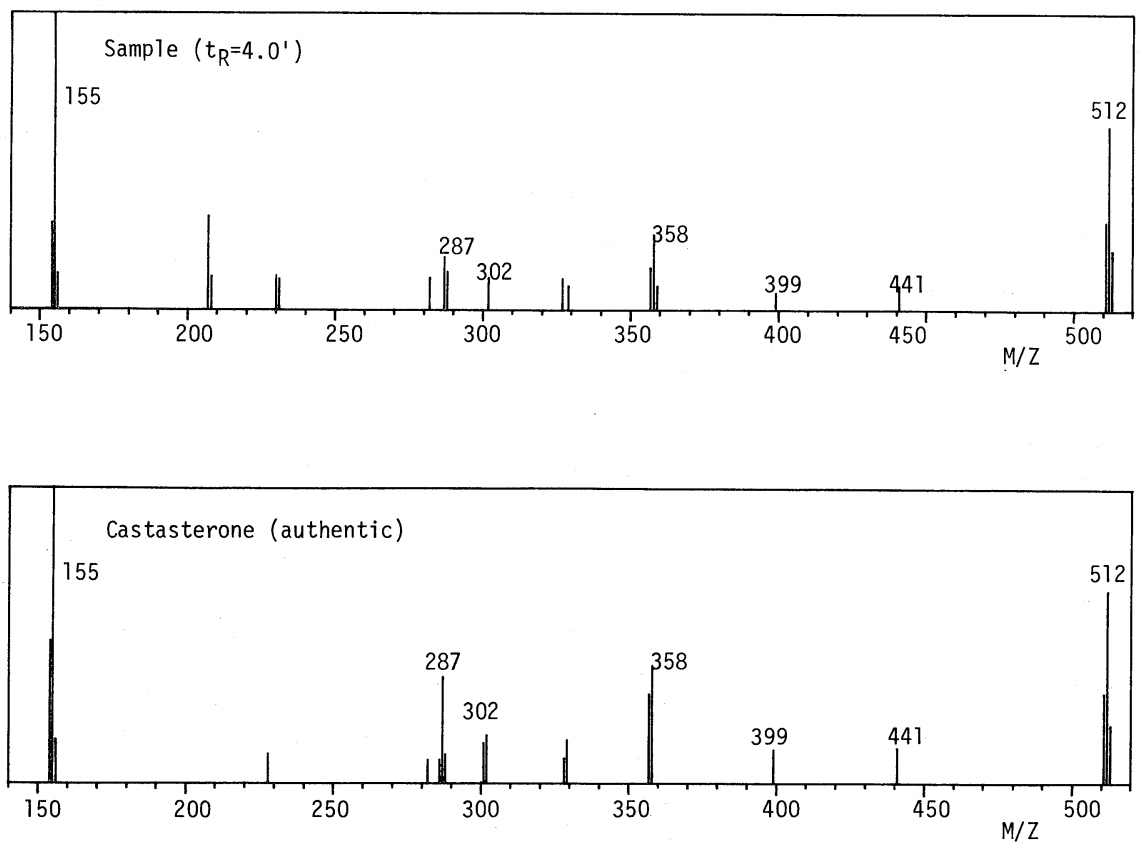

FIG. 5. Mass Spectra of Bismethaneboronates of the Active Fractions and Authentic Castasterone.

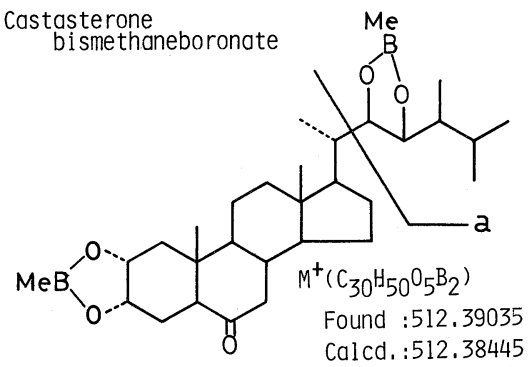

FIG. 6. Structure of Castasterone Bismethaneboronate.

cleavage (split a) of the derivatives (Fig. 6).

The full spectrum at $t_{R} 3.3 \mathrm{~min}$ is similar to that of castasterone bismethaneboronate (Fig. 7). However, the relative intensity of the ions of $m / z 498$ to those of $m / z 512$ was much larger than that of castasterone bismethaneboronate. High resolution MS showed the composition of the ions of $m / z 498$ to be $\mathrm{C}_{29} \mathrm{H}_{48} \mathrm{O}_{5} \mathrm{~B}_{2}$ (calcd. 498.36877), which is identical to the molecular formula of the bismethaneboronate of brassinone (Fig. 8). Thus, the full spectrum at $t_{R} 3.3 \mathrm{~min}$ was concluded to be the spectrum of a brassinone derivative at $t_{R} 3.3$ min overlapping with the leading of the castasterone derivatives at $t_{R} 4.0 \mathrm{~min}$, because the rather broad leading of the bismethaneboronate of castasterone was always observed.

Eight ninths of Fr. A from Shodex H-2001 was also submitted to HPLC on Nucleosil 5CN eluted with acetonitrile-water and afforded four active fractions (A-CN-1 to A$\mathrm{CN}-4)$. The most active fraction (A-CN-3) was crystallized from a mixture of acetonitrile and water, and was identified to be castasterone by GC/MS analysis as its bismethaneboronate.

Since the existence of castasterone and brassinone in Fr. A was suggested by the preliminary experiment using Fr. B, we tried to separate castasterone and brassinone in the remaining fractions $\mathrm{A}-\mathrm{CN}-1, \mathrm{~A}-\mathrm{CN}-2$ and $\mathrm{A}-$ $\mathrm{CN}-4$. These three fractions were combined and subjected to HPLC on Nucleosil $5 \mathrm{C}_{18}$ eluted with acetonitrile-water, which enabled the separation of castasterone and brassinone. Two fractions, ODS-casta and ODS-brass, were separately subjected to GC/SIM analysis after treatment with methaneboronic acid in pyridine. 

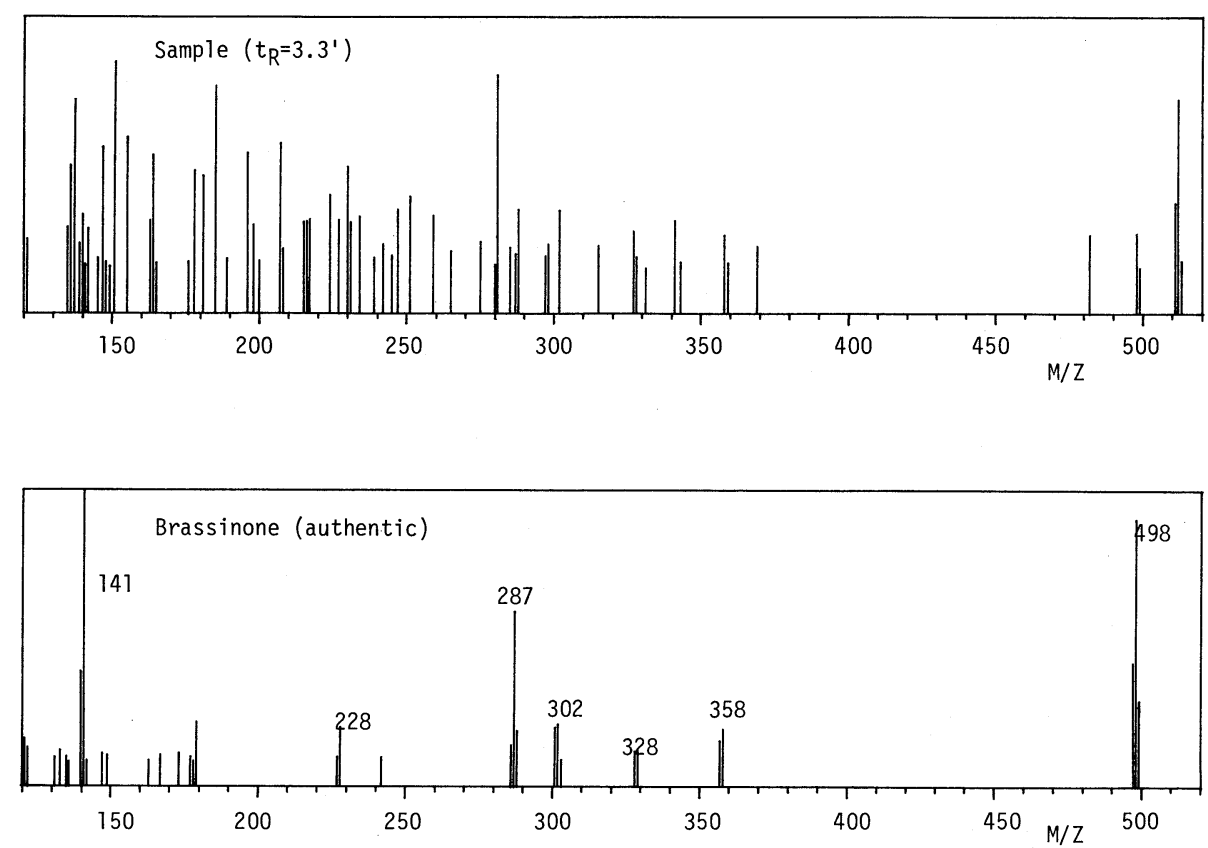

FIG. 7. Mass Spectra of Bismethaneboronates of the Active Fractions and Authentic Brassinone.

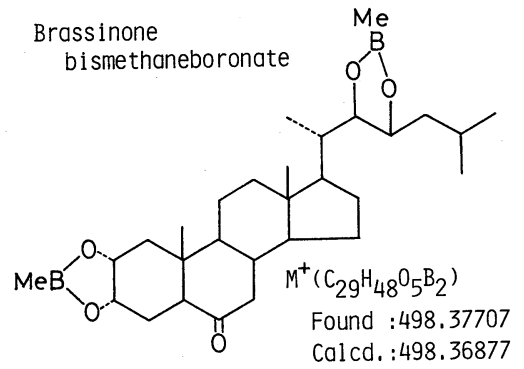

Fig. 8. Structure of Brassinone Bismethaneboronate.

From the ODS-casta fraction, peaks of $\mathrm{m} / \mathrm{z}$ 512,358 and 287 were observed at $t_{R} 3.5 \mathrm{~min}$. Both the $t_{R}$ and the proportions of the peak heights were identical with those of authentic castasterone bismethaneboronate (Fig. 9). From the ODS-brass fraction, peaks of $\mathrm{m} / z$ 498,358 and 287 were observed at $t_{R} 2.95 \mathrm{~min}$. Both the $t_{R}$ and the proportions of the peak heights were identical with those of authentic brassinone bismethaneboronate (Fig. 10). Thus, Fr. A, which was obtained by GPC as the main active fraction, was found to involve castasterone and brassinone. The occurrence of other brassinolide homologues was examined by GC/SIM using Fr. A. Ions of $m / z 510$,
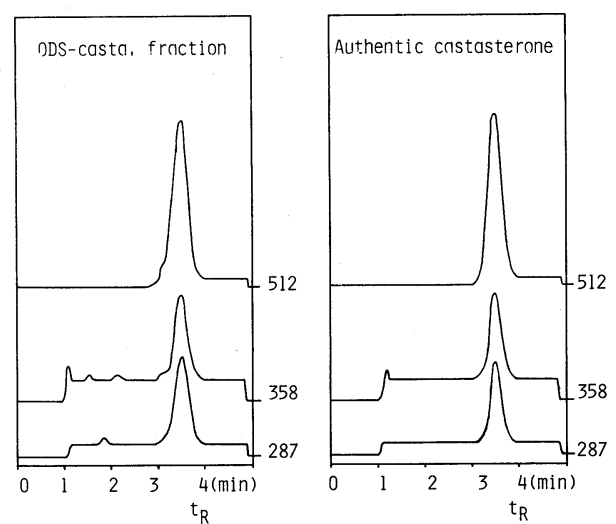

FIG. 9. GC/SIM Profile Identifying Castasterone from the ODS-Casta Fraction.

$514,524,526,528,540$ and 542 were monitored, which are molecular ions of dolichosterone, 28-norbrassinolide, homodolichosterone, dolicholide and (24S)-24-ethylbrassinone, brassinolide, homodolicholide and homobrassinolide, respectively. No homologues other than castasterone and brassinone were found.

Using one ninth of the main active fraction A, the contents of castasterone and brassinone 

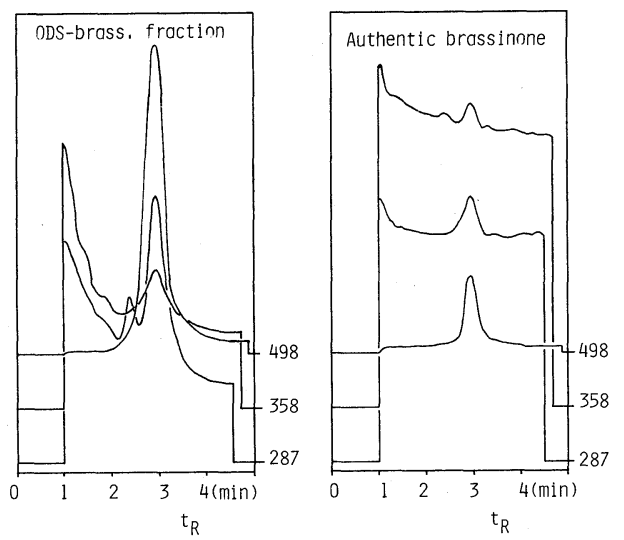

FIG. 10. GC/SIM Profile Identifying Brassinone from the ODS-Brass Fraction.

in this fraction were determined by means of GC/SIM, castasterone and brassinone being shown to exist in $30.0 \mu \mathrm{g}$ and $5.85 \mu \mathrm{g}$ amounts, respectively. Judging from this quantification result, the endogenous concentration of castasterone and brassinone is about $1.1 \mu \mathrm{g} / \mathrm{kg}$ f.w. and $0.2 \mu \mathrm{g} / \mathrm{kg}$ f.w., since their content in Fr. B was determined to be only one tenth of that in Fr. A by a bioassay. The content of castasterone was lower than that in the gall, stem, leaf and flower bud of Castanea crenata ${ }^{9)}$ or the shoot of Picea sitchensis. ${ }^{10)}$ but approximately equal to that in the seed of Dolichos lablab $^{10)}$ and the pollen of Pinus thunbergii. ${ }^{10)}$ The content of brassinone was higher than that in the seed and pod of Brassica campestris ${ }^{11)}$ or the leaf of Thea sinensis. ${ }^{11)}$

Due to the biological activity of castasterone and its oxidation level in the B ring, it has been considered to be a possible biosynthetic precursor of brassinolide and might show biological activity after the conversion to brassinolide. ${ }^{1)}$ In this study, however, none of the brassinolide homologues possessing a sevenmembered lactone in the $\mathrm{B}$ ring were detected by GC/SIM. If they existed, their contents must have been extremely low judging from the result of the bioassay. This may suggest that the ketonic homologues may play physiological roles by themselves during seed maturation and seed germination in $P$. purpurea. as has been reported by Wada et al. ${ }^{12)}$
Recently, many other brassinolide homologues have been identified from various species of plants, ${ }^{13 \sim 14)}$ and this kind of sterol is becoming a large family of plant growth regulators.

\section{EXPERIMENTAL}

Instrumental analyses.

a) A Hitachi M-80A mass spectrometer was used for GC/MS and GC/SIM, and a JEOL DX-300 mass spectrometer for $\mathrm{GC} /$ high resolution $\mathrm{MS}$. Their conditions were as follow. M-80A: ionization, EI $(22 \mathrm{eV})$; ionization chamber temp., $180^{\circ} \mathrm{C}$; column, $2 \%$ OV-1 on chromosorb $\mathrm{W}$ in a silanized column $(1 \mathrm{~m} \times 3 \mathrm{~mm}$ i.d. $)$; column temp., $270^{\circ} \mathrm{C}$; He flow, $45 \mathrm{ml} / \mathrm{min}$. DX-300: ionization, EI $(22 \mathrm{eV})$; ionization chamber temp., $180^{\circ} \mathrm{C}$; column, $2 \%$ OV-1 on chromosorb W $(1 \mathrm{~m} \times 3 \mathrm{~mm}$ i.d. $)$; column temp., $270^{\circ} \mathrm{C}$; He flow, $40 \mathrm{ml} / \mathrm{min}$.

b) Bismethaneboronation. Samples were converted into the bismethaneboronate, treating with $0.2 \%$ methaneboronic acid in pyridine at $60^{\circ} \mathrm{C}$ for $40 \mathrm{~min}$.

\section{Purification of castasterone and brassinone.}

a) Extraction and concentration. Immature seeds $(27 \mathrm{~kg})$ of Pharbitis purpurea were extracted with $80 \%$ acetone using a blender. The acetone was evaporated in vacuo to give an aqueous solution (30 liters).

b) Solvent fractionation. The aqueous solution was extracted with benzene and the organic phase was washed with saturated $\mathrm{NaHCO}_{3}$. The organic solution was dried over anhydrous $\mathrm{Na}_{2} \mathrm{SO}_{4}$ and concentrated to give the benzene-soluble neutral fraction $(278 \mathrm{~g})$.

c) Countercurrent distribution. The benzene-soluble neutral gum $(278 \mathrm{~g})$ was purified by a five-transfer countercurrent distribution between each 1 liter of methanol-water $(9: 1)$ and hexane-benzene (9:1). Among the six fractions (Fr. 1 6) thus obtained, fractions 1 and 2 showed activity on the rice (Koshihikari)-lamina inclination test, and these two fractions were combined $(103.6 \mathrm{~g})$ to be submitted to further purification.

d) Silica gel adsorption chromatography (I). The active gum (103.6 g) obtained in c) was charged on a column packed with $600 \mathrm{~g}$ of silica gel. The column was successively eluted with 3 liters of benzene, 60\% EtOAc in benzene, $80 \%$ EtOAc in benzene and EtOAc, and then by an increasing concentration of methanol in EtOAc up to $20 \%$ in $5 \%$ steps for each 3 liters. The column was finally washed with 3 liters of methanol. Active substances were eluted in the fraction of $10 \%$ methanol in EtOAc $(4.8 \mathrm{~g})$.

e) Silica gel adsorption chromatography (2). The active fraction $(4.8 \mathrm{~g})$ in $\mathrm{d})$ was charged on a column packed with $100 \mathrm{~g}$ of silica gel. The column was eluted with chloroform containing an increasing concentration of methanol up to $10 \%$ in $1 \%$ steps for each $500 \mathrm{ml}$ and then with 1 liter of methanol. The fractions $(138.2 \mathrm{mg})$ eluted 
with $4 \sim 5 \%$ methanol in chloroform were biologically active.

f) High performance gel permiation chromatography. The active fractions $(138.2 \mathrm{mg})$ in e) were combined and subjected to high performance gel permiation chromatography on Shodex H-2001 $(500 \times 20 \mathrm{~mm})$ eluted with THF at a flow rate of $3.2 \mathrm{ml} / \mathrm{min}$ (temperature, ambient; detection, RI). Active substances were eluted in $t_{R} 20^{\prime} \sim 21^{\prime}$ (Fr. A, $10.5 \mathrm{mg}$ ) and $t_{R} 21^{\prime} \sim 22^{\prime}$ (Fr. B, $5.4 \mathrm{mg}$ ).

g) High performance liquid chromatography (1). Both Fr. A and Fr. B in f) were submitted to high performance liquid chromatography on Nucleosil $5 \mathrm{CN}(200 \times 6 \mathrm{~mm})$ eluted with acetonitrile-water; from 0 to $5 \mathrm{~min}$, the acetonitrile content was kept at $20 \%$ and from 5 to $40 \mathrm{~min}$, the content was increased in $2.3 \%$ steps each minute. The flow rate was $1.0 \mathrm{ml} / \mathrm{min}$ and the column temperature was $40^{\circ} \mathrm{C}$. A UV detector was used for detection at $205 \mathrm{~nm}$. From Fr. A, four active fractions (A-CN-1 to A-CN-4) were obtained, and from Fr. B, four active fractions (B$\mathrm{CN}-1$ to B-CN-4) were obtained.

h) High performance liquid chromatography (2). Fr. A-CN-1,2 and 4 in g) were combined and subjected to HPLC on Nucleosil $5 \mathrm{C}_{18}(250 \times 8 \mathrm{~mm})$ to separate the castasterone and brassinone, eluting with acetonitrile-water $(4: 6)$ at a flow rate of $3.0 \mathrm{ml} / \mathrm{min}$. The column temperature was $50^{\circ} \mathrm{C}$ and the eluate was monitored with a UV detector at $205 \mathrm{~nm}$.

i) Crystallization. Fr. A-CN-3 in g) was dissolved in acetonitrile and then a very small amount of water was added. By evaporating the acetonitrile in part by flowing nitrogen gas, a small quantity of crystals were obtained. This substance was identified to be castasterone by GC/MS analysis as its bismethaneboronate.

j) Quantification. The castasterone and brassinone contained in Fr. A in f) were quantified by GC/SIM analysis, monitoring the ions of $\mathrm{m} / \mathrm{z} 5.12$ and $\mathrm{m} / \mathrm{z} 498$ for bismethaneboronates of castasterone and brassinone, respectively.

Acknowledgments. The authors are very grateful to Dr. T. Yokota of the University of Tokyo for his useful suggestions and advice, and to Dr. K. Mori of the University of Tokyo and Dr. N. Ikekawa of the Tokyo Institute of Technology for their gifts of authentic castasterone and brassinone, respectively. Thanks are also expressed to Dr. K. Aizawa of the University of Tokyo for the mass spectrometric analysis.

\section{REFERENCES}

1) M. D. Grove, G. F. Spencer, W. K. Rohwedder, N. Mandava, J. F. Woeley, J. D. Warthen, Jr., G. L. Steffence, J. L. Flippen-Anderson and J. C. Cook, Jr., Nature, 281, 216 (1979).

2) T. Yokota, M. Arima and N. Takahashi, Tetrahedron Lett., 23, 1275 (1982).

3) T. Yokota, J. Baba and N. Takahashi, Tetrahedron Lett., 23, 4965 (1982).

4) J. Baba, T. Yokota and N. Takahashi, Agric. Biol. Chem., 47, 659 (1983).

5) T. Yokota, J. Baba and N. Takahashi, Agric. Biol. Chem., 47, 1409 (1983).

6) H. Abe, T. Morishita, M. Uchiyama, S. Marumo, K. Munakata, S. Takatsuto and N. Ikekawa, Agric. Biol. Chem., 46, 2609 (1982).

7) K. Wada, S. Marumo, N. Ikekawa, M. Morisaki and K. Mori, Plant Cell Physiol., 22, 323 (1981).

8) S. Takatsuto, B. Ying, M. Morisaki and N. Ikekawa, J. Chromatogr., 239, 233 (1982).

9) M. Arima, T. Yokota and N. Takahashi, Phytochemistry, 23, in press (1984).

10) Personal communication from Dr. T. Yokota.

11) N. Ikekawa, S. Takatsuto, T. Kitsuwa, H. Saito, T. Morishita and H. Abe, J. Chromatogr., 290, 289 (1984).

12) K. Wada, S. Marumo, H. Abe, T. Morishita, K. Nakamura, M. Uchiyama and K. Mori, Agric. Biol. Chem., 48, 719 (1984).

13) T. Yokota, M. Morita and N. Takahashi, Agric. Biol. Chem., 47, 2149 (1983).

14) T. Yokota, M. Arima and N. Takahashi, Agric. Biol. Chem., 47, 2419 (1983). 